\title{
Catastrophic Natural Disasters and Economic Growth*
}

\author{
Eduardo Cavallo \\ Inter-American Development Bank \\ Research Department \\ Ilan Noy \\ University of Hawaii \\ Department of Economics
}

\author{
Sebastian Galiani \\ Washington University \\ in St. Louis \\ Juan Pantano \\ Washington University \\ in St. Louis
}

April 28, 2010

\begin{abstract}
We examine the short and long run average causal impact of catastrophic natural disasters on economic growth by combining information from comparative case studies. We assess the counterfactual of the cases studied by constructing synthetic control groups taking advantage of the fact that the timing of large sudden natural disasters is an exogenous event. We find that only extremely large disasters have a negative effect on output both in the short and long run. However, we also show that this result from two events where radical political revolutions followed the natural disasters. Once we control for these political changes, even extremely large disasters do not display any significant effect on economic growth. We also find that smaller, but still very large natural disasters, have no discernible effect on output in the short run or in the long run.
\end{abstract}

Key Words: Natural Disasters, Political Change, Economic Growth and Causal Effects.

JEL Codes: O40, O47.

${ }^{*}$ We thank Oscar Becerra for excellent research assistance, and seminar participants at the IDB for very useful comments. The views and interpretations in this document are those of the authors and should not be attributed to the Inter-American Development Bank, or to any individual acting on its behalf. All remaining errors are our responsibility. 


\section{Introduction}

Large sudden natural disasters such as earthquakes, tsunamis, hurricanes, and floods generate destruction on impact. Recent events such as the Indian Ocean tsunami in 2004, hurricane Katrina in 2005, and the Haitian and Chilean earthquakes in 2010 have received worldwide media coverage, and there is an increasing sense of awareness among the general public about the destructive nature of disasters. Much research in both the social and natural sciences has been devoted to increasing our ability to predict disasters; while the economic research on natural disasters and their consequences is fairly limited. ${ }^{1}$ In this paper we contribute to close this gap by carefully examining the causal effect of large natural disaster occurrence on gross domestic output, both in the short and long run.

Growth theory does not have a clear cut answer on the question of whether natural disasters should affect economic growth. Traditional neo-classical growth models predict that the destruction of capital (physical or human) does not affect the rate of technological progress and hence, it might only enhance short-term growth prospects as it drives countries away from their balanced-growth steady states. In contrast, endogenous growth models provide less clear-cut predictions with respect to output dynamics. For example, models based on Schumpeter's creative destruction process may even ascribe higher growth as a result of negative shocks, as these shocks can be catalysts for re-investment and upgrading of capital goods (see, for example, Caballero and Hammour (1994)). In contrast, the AKtype endogenous growth models in which technology exhibits constant returns to capital predict no change in the growth rate following a negative capital shock; while endogenous growth models that exploit increasing returns to scale in production generally predict that a destruction of part of the physical or human capital stock results in a lower growth path and consequently a permanent deviation from the previous growth trajectory.

Thus, the question of whether natural disasters affect economic growth is ultimately an empirical one; precisely the one we address in this study. ${ }^{2}$ Few papers have attempted to

\footnotetext{
${ }^{1}$ In particular, very little is known about whether output losses in the aftermath of natural disasters are recovered. This is an important question for the development literature. In two recent papers, Barro (2006 and 2009) has shown that the infrequent occurrence of economic disasters has much larger welfare costs than continuous economic fluctuations of lesser amplitude. However, we still do not know much about the aggregate effects of natural disasters.

${ }^{2}$ The macroeconomic literature generally distinguishes between short-run effects (usually up to five years),
} 
answer this question, and althought the evidence is pointing towards the conclusion that large natural disasters negatively affect economic growth in the short term, it is still inconclusive (see Cavallo and Noy, 2009). Furthermore, the bulk of the empirical evidence available focuses on the short-run effects. ${ }^{3}$

We contribute to this literature by bringing a new methodological approach to answer the question of sign and size of the short and long run effects of large natural disasters on growth. In particular, following Abadie et al. (2010), we pursue a comparative event study approach, taking advantage of the fact that the timing of a large sudden natural disaster is an exogenous event. The idea is to construct an appropriate counterfactual-i.e., what would have happened to the path of gross domestic product (GDP) of the affected country in the absence of natural disasters - and to assess the disaster's impact by comparing the counterfactual to the actual path observed. Importantly, the counterfactuals are not constructed by extrapolating pre-event trends from the treated countries but rather, following Abadie and Gardeazabal (2003), by building a synthetic control group-i.e., using as a control group other 'untreated' countries that, optimally weighted, estimate the missing counterfactual of interest. Given the macro nature of the question we investigate, we believe this methodology provides the best feasible identification strategy of the parameter of interest. To the best of our knowledge, ours is the first paper that applies this quasi-experimental design to a topic within the economic growth literature.

In the cross-country comparative case studies we describe here, we compare countries affected by natural disasters to a group of unaffected countries. The analysis is only feasible when some countries are exposed and others are not. Thus, we focus our analysis only on large events, rather than on recurrent events that are prevalent everywhere. Moreover, the methodology requires that we can trace the evolution of the outcome variable for several

and longer-run effects (anything beyond that horizon). The first recent attempt to empirically describe shortrun macroeconomic dynamics following natural disasters is Albala-Bertrand (1993). In a related literature, Kahn (2004) and Kellenberg and Mobarak (2008) study the relationship between economic development and vulnerability to natural disasters. Yang (2008) studies the impact of hurricanes on international finantial flows.

${ }^{3}$ For example, using a Panel Vector Autoregression (VAR) framework on a sample of low income countries, Raddatz (2007) finds that natural disasters have an adverse short-run impact on output dynamics. Noy (2009) finds a similar result exploiting cross country variability by means of the Hausman-Taylor random effects estimator. See Cavallo and Noy (2009) for a detailed survey of this literature. 
years after the event. For that reason, we limit the sample to disasters that occur before the year 2000. In addition, we adapt the synthetic control methods developed by Abadie and Gardeazabal (2003) and Abadie et al. (2010) to combine information from several large disasters.

From the outset, we stress that we are not testing nor distinguishing among alternative growth theories of the relationship between natural disasters and economic growth. Instead, we attempt to rigorously establish the direction and magnitude of the average causal effect of large natural disasters on economic growth, which is an important piece of evidence not yet conclusively established in the literature.

Our results show that only very large disasters -whereby "large" is defined in relation to the distribution of direct damages caused by natural events - display an impact on GDP growth in the affected countries, both in the short- and in the long-run. The effects are both statistically significant and economically meaningful. For example, ten years after the disaster, the average GDP per capita of the affected countries is (on average) $10 \%$ lower that it was at the time of the disaster whereas it would be about $18 \%$ higher in the counterfactual scenario in which the disaster did not occur. However, these large effects are all driven by events that were followed by radical political revolution (these are the cases of the Islamic Iranian Revolution (1979) and the Sandinista Nicaraguan Revolution (1979)). Those not followed by radical political changes do not show significant subsequent effects on economic growth. For milder events, we do not find evidence of any significant impact on GDP growth either in the short- or in the long-run.

Thus, we find that only very large natural disasters followed by radical political revolution show long-lasting negative economic effects on economic growth. Even very large natural disasters, when not followed by disruptive political reforms that alter the economic system, including the system or property rights, do not display significant effects on economic growth.

The structure of the paper is as follows. Section 2 presents the empirical methodology and Section 3 describes the data. Results are discussed in Section 4. Conclusions follow. 


\section{Empirical Methodology}

Identification of the causal effect of natural disasters on economic growth is difficult. Exploiting cross-sectional variability, and assuming that natural disasters indeed affect negatively the level, and perhaps also, the rate of growth of GDP (per capita), estimates of the effect of natural disasters on GDP are likely to be severely biased upward (in absolute value) due to the fact that, ceteris paribus, the magnitude of natural disasters is larger among poor countries. Though stratifying the analysis by income level might help to attenuate this omitted variable bias, it can hardly be argued that it would solve the problem.

A natural solution is to rely on longitudinal data to control for time-invariant unobservable variables. Nevertheless, exploiting the within country variability requires that the group of countries that are not shocked by natural disasters (i.e., the control group) allow us to estimate what would have been the growth rates of the affected countries (i.e., the treatment group) in the absence of the shocks. Unfortunately, this assumption is difficult to be satisfied

in general. If, for example, the countries in the control group, on average, were to grow at a faster rate than those affected by natural disasters even in the absence of these shocks, panel data estimates will also tend to be biased upward (in absolute value). One can attempt to control for the differential trends across countries by controlling for country specific trends in the econometric model. This entails extrapolating to the post-shock period the pre-shock trends, which is a strong assumption, especially over long-periods of time.

Essentially, to overcome the problems of identification outlined above, we need to find a group of countries that: a) have had the same secular trends in the dependent variable analyzed (i.e., GDP or GDP growth rates) and b) likely would have had the same secular behavior in the absence of the shocks studied. We can then use this group to estimate the counterfactual and conduct a causal analysis. We do this by adopting a novel methodological approach: comparative case studies. This approach is more general than the fixed-effects model commonly applied in the empirical literature. The fixed effects model allows for the presence of unobserved confounders but restricts the effect of those confounders to be constant in time. Instead, the approach we adopt here allows the effects of confounding unobserved characteristics to vary with time. Below we describe this approach in detail. 


\subsection{Estimating the Impact of Large Disasters with Comparative Case Studies}

Case studies focus on particular occurrences of the interventions of interest. In a case study one is usually interested in finding the effects of an event or policy intervention on some outcome of interest. In a cross-country comparative case study, we compare countries affected by the event of interest (in our case a large natural disaster) to a group of unaffected countries. We first focus on establishing some notation to evaluate the effect of a large disaster for a single country. We will later aggregate the country specific effects into an average effect.

We observe $J+1$ countries. Without loss of generality, let the first country be the one exposed to a large natural disaster, so that we have $J$ remaining countries that serve as potential controls or "donors". In comparative case studies it is assumed that the treated unit is uninterruptedly exposed to treatment after some initial intervention period. In our case we consider the occurrence of the catastrophic event as the initiation of the intervention period (which includes the disaster's aftermath).

Following Abadie et al. (2010), let $Y_{i t}^{N}$ be the GDP per capita that would be observed for country $i$ at time $t$ in the absence of the disaster, for countries $i=1, \ldots ., J+1$, and time periods $t=1, \ldots ., T$. Let $T_{0}$ be the number of periods before the disaster, with $1 \leq T_{0}<T$. Let $Y_{i t}^{I}$ be the outcome that would be observed for country $i$ at time $t$ if country $i$ is exposed to the disaster and its aftermath from period $T_{0}+1$ to $T$. Of course, to the extent that the occurrence of a large disaster is unpredictable, it has no effect on the outcome before the intervention, so for $t \in\left\{1, \ldots \ldots, T_{0}\right\}$ and all $i \in\{1, \ldots \ldots, N\}$, we have that $Y_{i t}^{I}=Y_{i t}^{N}$. ${ }^{4}$

Let $\alpha_{i t}=Y_{i t}^{I}-Y_{i t}^{N}$ be the effect of the disaster for country $i$ at time $t$, if country $i$ is exposed to the intervention in periods $T_{0}+1, T_{0}+2, \ldots \ldots, T$ (where $1 \leq T_{0}<T$ ). Note that we allow this effect to potentially vary over time. Again, the intervention, in our context, is

\footnotetext{
${ }^{4}$ The assumed unpredictability of natural disasters is not inconsistent with the fact that some countries are more prone to others to suffer natural disasters. In a sense this risk is already discounted and may influence the steady state growth rate of the country. But, conditional on this underlying propensity, the specific timing of ocurrence is unpredictable.
} 
the disaster and its aftermath. Therefore:

$$
Y_{i t}^{I}=Y_{i t}^{N}+\alpha_{i t}
$$

Let $D_{i t}$ be an indicator that takes value one if country $i$ is exposed to the intervention at time $t$, and value zero otherwise. The observed output per capita for country $i$ at time $t$ is

$$
Y_{i t}=Y_{i t}^{N}+\alpha_{i t} D_{i t}
$$

Because only the first country (country "one") is exposed to the intervention and only after period $T_{0}$ (with $1 \leq T_{0}<T$ ), we have that:

$$
D_{i t}=\left\{\begin{array}{cc}
1 & \text { if } i=1 \text { and } t>T_{0} \\
0 & \text { otherwise }
\end{array}\right.
$$

Our parameters of interest are $\left(\alpha_{1, T_{0}+1}, \ldots \ldots, \alpha_{1, T}\right)$, the lead-specific causal effect of the catastrophic event on the outcome of interest. For $t>T_{0}$,

$$
\alpha_{1 t}=Y_{1 t}^{I}-Y_{1 t}^{N}=Y_{1 t}-Y_{1 t}^{N}
$$

Note that $Y_{1 t}^{I}$ is observed. Therefore, to estimate $\alpha_{1 t}$ we will only need to come up with an estimate for $Y_{1 t}^{N}$.

Suppose that $Y_{i t}^{N}$ is given by a factor model:

$$
Y_{i t}^{N}=\delta_{t}+\theta_{t} Z_{i}+\lambda_{t} \mu_{i}+\varepsilon_{i t}
$$

where $\delta_{t}$ is an unknown common factor with constant factor loadings across countries, $Z_{i}$ is a $(r \times 1)$ vector of observed predictors for GDP per capita (not affected by the natural disaster $), \theta_{t}$ is a $(1 \times r)$ vector of unknown parameters, $\lambda_{t}$ is a $(1 \times F)$ vector of unobserved common factors, $\mu_{i}$ is an $(F \times 1)$ vector of unknown factor loadings, and the error terms $\varepsilon_{i t}$ are unobserved transitory GDP per capita shocks at the country level with zero mean for all $i$ and $t$. This model does not rule out the existence of time-varying measured determinants 
of $Y_{i t}^{N}$. The vector $Z_{i}$ may contain pre- and post-disaster values of time-varying variables, as long as they are not affected by the disaster. The most widely used version of this model in the literature assumes constant effects for each regressor and simplifies to the following model:

$$
Y_{i t}^{N}=\delta_{t}+\theta Z_{i t}+\lambda_{t} \mu_{i}+\varepsilon_{i t}
$$

Moreover, this boils down to the simpler fixed-effects model if $\lambda_{t}$ is constant for all $t$. This restricted model could be easily estimated by a difference-in-differences estimator.

Now, consider a $(J \times 1)$ vector of weights $W=\left(w_{2}, \ldots ., w_{J+1}\right)^{\prime}$ such that $w_{j} \geq 0$ for $j=2, \ldots \ldots ., J+1$ and $w_{2}+w_{3}+\ldots . .+w_{J+1}=1$. Each particular value of the vector $W$ represents a potential synthetic control, that is, a particular weighted average of control countries.

The real GDP per capita for each synthetic control indexed by $W$ is:

$$
\sum_{j=2}^{J+1} w_{j} Y_{j t}=\delta_{t}+\theta_{t} \sum_{j=2}^{J+1} w_{j} Z_{j}+\lambda_{t} \sum_{j=2}^{J+1} w_{j} \mu_{j}+\sum_{j=2}^{J+1} w_{j} \varepsilon_{j t}
$$

Suppose that there exists a set of weights $\left(w_{2}^{*}, \ldots \ldots, w_{J+1}^{*}\right)$ satisfying $\sum_{j=2}^{J+1} w_{j}^{*}=1$ such that:

$$
\begin{array}{cc}
\sum_{j=2}^{J+1} w_{j}^{*} Y_{j 1}= & Y_{1,1} \\
& \vdots \\
\sum_{j=2}^{J+1} w_{j}^{*} Y_{j, T 0} & =Y_{1, T 0} \\
\sum_{j=2}^{J+1} w_{j}^{*} Z_{j} & =Z_{1}
\end{array}
$$

Then, it can be shown that if $\sum_{t=1}^{T 0} \lambda_{t}^{\prime} \lambda_{t}$ is non-singular,

$$
Y_{1 t}^{N}-\sum_{j=2}^{J+1} w_{j}^{*} Y_{j t}=\sum_{j=2}^{J+1} w_{j}^{*} \sum_{s=1}^{T_{0}} \lambda_{t}\left(\sum_{n=1}^{T_{0}} \lambda_{n}^{\prime} \lambda_{n}\right)^{-1} \lambda_{s}^{\prime}\left(\varepsilon_{j s}-\varepsilon_{1 s}\right)-\sum_{j=2}^{J+1} w_{j}^{*}\left(\varepsilon_{j t}-\varepsilon_{1 t}\right)
$$

Abadie, Diamond and Hainmueller (2010) show that, under standard conditions, the right 
hand side of this equation will be close to zero (in expectation) if the number of pre-disaster periods is large relative to the scale of $\varepsilon$. Therefore, they suggests using

$$
\widehat{\alpha}_{1 t}=Y_{1 t}-\sum_{j=2}^{J+1} w_{j}^{*} Y_{j t}
$$

for $t \in\left\{T_{0}+1, \ldots \ldots \ldots, T\right\}$ as an estimator of $\alpha_{1 t}$.

The system of equations in (5), (6) and (7) can hold exactly only if $\left(Y_{1,1}, \ldots \ldots ., Y_{1, T_{0}} ; Z_{1}^{\prime}\right)$ belongs to the convex hull of

$$
\left\{\left(Y_{2,1}, \ldots \ldots . ., Y_{2, T_{0}} ; Z_{2}^{\prime}\right), \ldots . .,\left(Y_{J+1,1}, \ldots, Y_{J+1, T_{0}} ; Z_{J+1}^{\prime}\right)\right\}
$$

In practice, it is often the case that no set of weights exists such that these equations hold exactly in the data. Then, the synthetic control country will be selected so that they hold approximately.

\subsection{Computational Issues}

The outcome variable of interest, say GDP per capita, is observed for $T$ periods for the country affected by the catastrophic event $Y_{1 t},(t=1, \ldots \ldots, T)$ and the unaffected countries $Y_{j t},(j=2, \ldots ., J+1 ; t=1, \ldots ., T)$. Let $T_{1}=T-T_{0}$ be the number of available postdisaster periods. Let $Y_{1}$ be the $\left(T_{1} \times 1\right)$ vector of post-disaster outcomes for the exposed country, and $Y_{0}$ be the $\left(T_{1} \times J\right)$ matrix of post-disaster outcomes for the potential control countries. Let the $\left(T_{0} \times 1\right)$ vector $K=\left(k_{1}, \ldots \ldots, k_{T_{0}}\right)$ define a linear combination of predisaster outcomes: $\bar{Y}_{i}^{K}=\sum_{s=1}^{T_{0}} k_{s} Y_{i s}$. Consider $M$ of such linear combinations defined by the vectors $K_{1}, \ldots \ldots, K_{M}$. Let $X_{1}=\left(Z_{1}^{\prime} ; \bar{Y}_{1}^{K_{1}}, \ldots ., \bar{Y}_{1}^{K_{M}}\right)^{\prime}$ be a $(k \times 1)$ vector of pre-disaster output linear combinations and output predictors not affected by the disaster for the exposed country, with $k=r+M$. Similarly, let $X_{0}$ be a $(k \times J)$ matrix that contains the same variables for the unaffected countries. That is, the $j^{t h}$ column of $X_{0}$ is $\left(Z_{j}^{\prime} ; \bar{Y}_{j}^{K_{1}}, \ldots ., \bar{Y}_{j}^{K_{M}}\right)^{\prime}$.

The vector $W^{*}$ is chosen to minimize some distance, $\left\|X_{1}-X_{0} W\right\|$, between $X_{1}$ and $X_{0} W$, 
subject to $w_{2} \geq 0, \ldots ., w_{J+1} \geq 0$ and $\sum_{j=2}^{J+1} w_{j}^{*}=1$. In particular, we will consider

$$
\left\|X_{1}-X_{0} W\right\|_{V}=\sqrt{\left(X_{1}-X_{0} W\right)^{\prime} V\left(X_{1}-X_{0} W\right)}
$$

where $V$ is a $(k \times k)$ symmetric and positive semidefinite matrix.

Although this inferential procedure is valid for any choice of $V$, the choice of $V$ influences the mean square error of the estimator (that is, the expectation of $\left.\left(Y_{1}-Y_{0} W^{*}\right)^{\prime}\left(Y_{1}-Y_{0} W^{*}\right)\right)$. The optimal choice of $V$ assigns weights to a linear combination of the variables in $X_{0}$ and $X_{1}$ to minimize the mean square error of the synthetic control estimator. The choice of $V$ can also be data-driven. One possibility is to choose $V$ such that the resulting synthetic control country approximates the trajectory of the outcome variable of the affected country as well as outcome predictors in the pre-disaster periods. Indeed, we will choose $V$ such that the mean squared prediction error of the outcome variable is minimized for the preintervention periods. One obvious choice for the set of linear combinations of pre-disaster outcomes $\left(\bar{Y}_{i 1}^{K_{1}}, \ldots . ., \bar{Y}_{i 1}^{K_{M}}\right)$ would be

$$
\begin{array}{cc}
\bar{Y}_{i 1}^{K_{1}}= & Y_{i 1} \\
& \vdots \\
\bar{Y}_{i 1}^{K_{T_{0}}}= & Y_{i T_{0}}
\end{array}
$$

This would in essence include the entire pre-disaster output per capita path as input to build the synthetic control. Alternatively, we can use the first half of the pre-disaster trend outcomes to match the affected country with the donors. ${ }^{5}$ That is $\left(\bar{Y}_{i 1}^{K_{1}}, \ldots . ., \bar{Y}_{i 1}^{K_{M}}\right)$ would be

$$
\begin{aligned}
\bar{Y}_{i 1}^{K_{1}}= & \bar{Y}_{i 1}^{K_{1}}=Y_{i, 1} \\
& \vdots \\
\bar{Y}_{i 1}^{K_{M}}= & \bar{Y}_{i 1}^{K_{\frac{T_{0}-1}{2}}^{2}}=Y_{i, \frac{T_{0}-1}{2}}
\end{aligned}
$$

\footnotetext{
${ }^{5}$ This period varies across countries, depending on when the disaster occurs relative to the earliest year in our sample.
} 
Indeed, by only exploiting the first half of the pre-disaster trend to form the synthetic match, we are more confident in its ability to replicate the counterfactual trajectory.

In this paper, we extend the idea in Abadie et al. (2010) generalizing the placebo approach to produce quantitative inference in comparative case studies. We now discuss how to combine the placebo effects to account for the fact that we will be interested in doing inference about the average (normalized) effect found across the country specific comparative case studies of each disaster. ${ }^{6}$

Recall our lead specific estimates of the disaster on the country of interest (say, country 1) are denoted by $\left(\widehat{\alpha}_{1, T_{0}+1}, \ldots \ldots, \widehat{\alpha}_{1, T}\right)$ for leads $1,2, \ldots ., T-T_{0}$, Now consider taking the average disaster effect across $G$ disasters of interest, say, the $G$ largest disasters. Assume for simplicity that for all these $G$ disasters we are able to compute the $T-T_{0}$ lead specific estimates of disaster impact. Then the estimated average effect for the $G$ largest disasters is given by

$$
\bar{\alpha}=\left(\bar{\alpha}_{T_{0}+1}, \ldots \ldots, \bar{\alpha}_{T}\right)=\frac{1}{G} \sum_{g=1}^{G}\left(\widehat{\alpha}_{g, T_{0}+1}, \ldots \ldots, \widehat{\alpha}_{g, T}\right)
$$

\subsection{Statistical Significance of Estimated Effects}

The standard errors commonly reported in regression-based comparative case studies measure uncertainty about aggregate data. This mode of inference would logically produce zero standard errors if aggregate data were used for estimation. However, perfect knowledge of the value of aggregate data does not reduce to zero our uncertainty about the parameter of interest: the effect of a large disaster on output per capita. Not all uncertainty about the value of the estimated parameters come from lack of knowledge of aggregate data. In comparative case studies such as ours, an additional source of uncertainty derives from our ignorance about the ability of the control group to reproduce the counterfactual. There is some uncertainty about how the affected country would have evolved in the absence of the

\footnotetext{
${ }^{6}$ We match each country with its synthetic counterpart using the path of GDP per capita. Therefore, the estimated country specific effect of the disaster is measured as the difference in the actual and counterfactual evolution of GDP per capita. The size of the effect will depend on the level of GDP per capita. The same decline in GDP per capita is more important in a poorer country. Given these scale effects, we need to normalize the estimates before pooling the country specific results to come up with the average effect of a disaster. We normalize by setting the GDP per capita of the affected country (for each of the disasters we consider) to be equal to 1 , in the disaster year.
} 
disaster. Large sample inferential techniques are not well-suited for comparative case studies when the number of units in the comparison group and the number of periods in the sample are relatively small. Following Abadie and Gardeazabal (2003) and Abadie et al. (2010), we use exact inferential techniques, similar to permutation tests, to conduct inference in comparative case studies. These methods allow for valid inference regardless of the number of available donor countries and the number of available pre-disaster periods. However the quality of inference increases with the number of donor countries or the number of available time periods.

As in classical permutation tests, we apply the synthetic control method to every potential control in our sample. This allows us to assess whether the effect estimated by the synthetic control for the country affected by the disaster is large relative to the effect estimated for a country chosen at random (which was not exposed to a large disaster). This inferential exercise is exact in the sense that, regardless of the number of available comparison countries and time periods, it is always possible to calculate the exact distribution of the estimated effect of the placebo disasters. More generally, this inferential exercise examines whether or not the estimated effect of an actual natural disaster is large relative to the distribution of the effects estimated for the countries not exposed to such disasters. More formally, assume that we are doing inference about negative point estimates at every lead (every year in the disaster's aftermath). We can then compute a lead specific significance level (p-value) for the estimated disaster impact as

$$
\text { p-value }=\operatorname{Pr}\left(\widehat{\alpha}_{1, l}^{P L}<\widehat{\alpha}_{1, l}\right)=\frac{\sum_{j=2}^{J+1} I\left(\widehat{\alpha}_{1, l}^{P L(j)}<\widehat{\alpha}_{1, l}\right)}{\# \text { of donors }}=\frac{\sum_{j=2}^{J+1} I\left(\widehat{\alpha}_{1, l}^{P L(j)}<\widehat{\alpha}_{1, l}\right)}{J}
$$

where $\widehat{\alpha}_{1, l}^{P L(j)}$ is the lead $l$-specific effect of a disaster when donor country $j$ is assigned a placebo-disaster at the same time as country 1. $\widehat{\alpha}_{1, l}^{P L(j)}$ is computed following the same procedure outlined above for $\widehat{\alpha}_{1, l}$. By computing $\widehat{\alpha}_{1, l}^{P L(j)}$ for every country $j$ in the donor pool for country 1 , we can characterize the distribution of placebo effects and assess how the estimate $\widehat{\alpha}_{1, l}$ ranks in that distribution.

Now, to conduct valid inference for $\bar{\alpha}$ we need to account for the fact that the average smooths out some noise. We then construct a distribution of average placebo effects 
according to the following steps:

1. For each disaster $g$ of interest we compute all the placebo effects using the available donors $j_{g}=2, \ldots \ldots, J_{g}+1$ corresponding to disaster $g$

2. At each lead, we compute every possible placebo average effect by picking a single placebo estimate corresponding to each disaster $g$, and then taking the average across the $G$ placebos. There are many possible placebo averages:

$$
N_{\overline{P L}}=\text { Number of possible placebo averages }=\prod_{g=1}^{G} J_{g}
$$

Let's index all these possible placebo averages by $n p=1, \ldots, N_{\overline{P L}}$ This number grows very quickly in $G$ and the typical $J_{g}$.

3. We rank the actual lead specific average disaster effect $\bar{\alpha}_{l}$ in the distribution of $N_{\overline{P L}}$ average placebo effects (This involves $N_{\overline{P L}}$ comparisons)

4. We compute the lead $l$ specific p-value for the average as

$$
\begin{aligned}
\text { p-value }_{l} & =\operatorname{Pr}\left(\frac{1}{G} \sum_{g=1}^{G} \widehat{\alpha}_{g, l}^{P L}<\bar{\alpha}_{l}\right) \\
& =\operatorname{Pr}\left(\bar{\alpha}_{l}^{P L}<\bar{\alpha}_{l}\right) \\
& =\frac{\sum_{n p=1}^{N_{\overline{P L}}} I\left(\bar{\alpha}_{l}^{P L(n p)}<\bar{\alpha}_{l}\right)}{\# \text { of possible placebo averages }} \\
& =\frac{\sum_{n p=1}^{N_{\overline{P L}}} I\left(\bar{\alpha}_{l}^{P L(n p)}<\bar{\alpha}_{l}\right)}{N_{\overline{P L}}}
\end{aligned}
$$

\section{Data Description}

\subsection{Data Sources}

We exploit a comprehensive dataset of 196 countries covering the period 1970-2008. The data on real GDP per capita at purchasing power parities (PPP) comes from the World Bank World Development Indicators (WDI). Following a voluminous empirical growth literature 
(see, among others, Barro and Sala-i-Martin (2003) and Mankiw, Romer, and Weil (1992)), and attempting to maximize the pre-event fit of the models, the GDP predictors (i.e., vector $Z_{i}$ in equation 4) we use are (i) Trade Openness (real exports plus real imports over real GDP), from WDI; (ii) Capital Stock computed through the perpetual inventory method using data from the Penn World Tables (PWT) ${ }^{7}$ (iii) Land Area (in Km2); (iv) Population; (v) Secondary Education Attainment, from Lutz et al (2007), (vi) Latitude (in absolute value); and (vii) Polity 2 which is an aggregate indicator of democracy, from the Polity IV database (Marshall and Jaggers, 2002).

The data on natural disasters and their human and economic impacts is from the EMDAT database collected by the Centre for Research on the Epidemiology of Disasters (CRED) at the Catholic University of Louvain. The EM-DAT database has worldwide coverage, and contains data on the occurrence and effects of natural disasters from 1900 to the present. ${ }^{8}$ CRED defines a disaster as a natural event which overwhelms local capacity, necessitating a request for external assistance. For a disaster to be entered into the EM-DAT database at least one of the following criteria must be fulfilled: (1) 10 or more people has to be reported killed; (2) 100 people has to be reported affected; (3) state of emergency is declared; and/or (4) international assistance is called for. These disasters can be hydro-meteorological disasters including floods, wave surges, storms, droughts, landslides and avalanches; geophysical disasters - earthquakes, tsunamis and volcanic eruptions; and biological disasters covering epidemics and insect infestations (though these are much less frequent).

The EM-DAT database includes three measures of the magnitude of the disaster: (1) the number of people killed; (2) the number of people affected; and (3) the amount of direct damage (measured in United States dollars). ${ }^{9}$ Since we presume that the impact of a specific natural disaster on the economy depends on the magnitude of the disaster relative to the size of the economy, we standardize the three disaster measures. We divide the measures for the number of people killed or affected by the population size in the year prior to the

\footnotetext{
${ }^{7}$ We construct series for capital stock using data from the PWT. Total investment in PPP terms is obtained by multiplying the PPP adjusted investment ratios to GDP (ki) by real GDP per capita (rgdpl) and population (pop). Then, following the methodology presented in Easterly and Levine (2001), the perpetual inventory method is used to construct the capital stock.

${ }^{8}$ The data is publicly available at: http://www.cred.be/

${ }^{9}$ The amount of damage reported in the database consists only of direct damages (e.g. damage to infrastructure, crops, housing) and does not include indirect or secondary damages.
} 
disaster; and divide the direct cost measure of the disaster by the previous year's GDP.

In our econometric analysis in the next section we rely on the variable "number of people killed" -divided by total population- to define the magnitude of the natural disasters. Moreover, we focus primarily on the three types of disasters which are more common and for which the data is more reliable: earthquakes -including tsunamis-, floods and windstorms.

There are a total of 6,530 events recorded in the database between 1970 and 2008, of which $47.4 \%$ are floods, $40.1 \%$ are storms and $12.5 \%$ are earthquakes (Table 1 ). Often times there is more than one event recorded on a given country-year. In those cases we add up the corresponding disaster magnitudes and define a "combined" disaster for that country-year. From a first look at the data, disasters are fairly common. Out of a total of $(39 \times 196=)$ 7644 year-country observations, 34\% (that is, 2597 observations) meet the requirements to be designated as a natural disaster. In turn, these events are distributed between storms $(29 \%)$, floods $(38 \%)$ and "combined" (26\%). Earthquakes are much less frequent (7\% of the country-year observations).

Table 1: Distribution of disaster type 1970 - 2008

\begin{tabular}{llcc}
\hline & \multicolumn{1}{c}{ Disaster } & Observations & $(\%)$ \\
\cline { 2 - 4 } Disaster level & Earthquake & 816 & 12.5 \\
& Storm & 2,617 & 40.1 \\
& Flood & 3,097 & 47.4 \\
\cline { 2 - 4 } & Total & 6,530 & 100.0 \\
\hline \multirow{3}{*}{ Country-year level } & Earthquake & 179 & 6.9 \\
& Storm & 747 & 28.8 \\
& Flood & 996 & 38.4 \\
& Combined & 675 & 26.0 \\
\cline { 2 - 4 } & Total & 2,597 & 100.0 \\
\hline
\end{tabular}

Source: Authors' calculation based on EM-DAT

Moreover, as can be seen in Figure 1, there is a positive trend in the prevalence of total events over the sample period. However, this trend is somewhat deceptive as it appears to be driven by improved recording of mild events, rather than by an increase in the frequency of occurrence of total events. ${ }^{10}$ Furthermore, truly large events -i.e., conceivably more

\footnotetext{
${ }^{10}$ See Cavallo and Noy (2009) for a discussion of this issue.
} 
catastrophic - are rare. Both of these facts are shown in Figure 1 and Table 2 where we restrict the sample only to large events, and where "large" is defined in relation to the world mean of direct damage caused by natural disasters. ${ }^{11}$ As it is evident from Figure 1, there is no time trend for the subset of large events. Moreover, the frequency of occurrence of "large" disasters is significantly smaller than that of all events (right vs. left scales in Figure 1. See also Table 2). This suggests that there is a high incidence of small disasters in the sample or, more precisely, that the threshold for what constitutes a disaster (and hence gets recorded in the dataset) is quite lenient.

Table 2: Distribution of Disaster Type (large events) 1970 - 2008

\begin{tabular}{llcc}
\hline & \multicolumn{1}{c}{ Disaster } & Observations & \multicolumn{1}{c}{$(\%)$} \\
\cline { 2 - 4 } & Earthquake & 75 & 26.0 \\
Disaster level & Storm & 131 & 45.3 \\
& Flood & 83 & 28.7 \\
\cline { 2 - 4 } & Total & 289 & 100.0 \\
\hline & Earthquake & 24 & 18.6 \\
& Storm & 63 & 48.8 \\
Country-year level & Flood & 21 & 16.3 \\
& Combined & 21 & 16.3 \\
\cline { 2 - 4 } & Total & 129 & 100.0 \\
\hline Note: Large events refers to events whose intensity is above the mean of the \\
respective normalized distribution of number of people killed & \\
Source: Authors' calculation based on EM-DAT & &
\end{tabular}

It is important to notice that many of the events that are recorded in the dataset do not correspond to the catastrophic notion of natural disaster that one has in mind when thinking about the potential effect of natural disasters on the macro-economy. Therefore we will be focusing on disasters whose magnitudes are particularly large according to some precise thresholds to be defined below.

\footnotetext{
${ }^{11}$ Here, a 'large' disaster occurs when its incidence, measured in terms of people killed as a share of population, is greater than the world pooled mean for the entire sample period.
} 
Figure 1: Increasing Prevalence of Natural Disasters 1970 - 2007

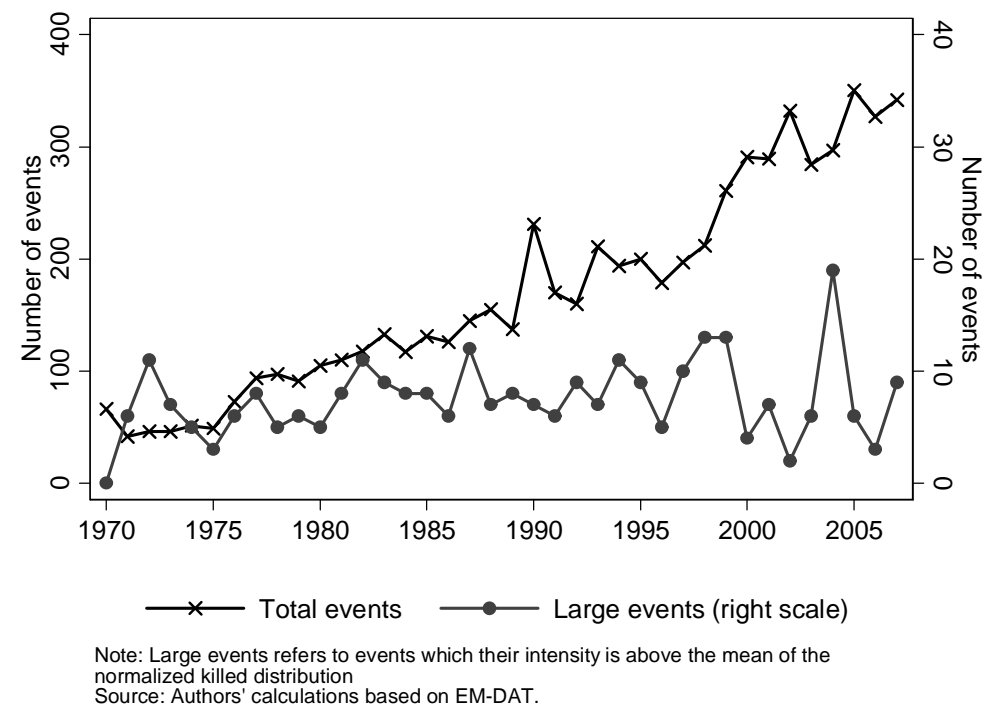

\subsection{Defining Large Disasters}

Our treatment effects methodology requires us to have a binary treatment indicator for the occurrence of a disaster. As a first approximation, we could define a large disaster as one in which the magnitude is more than, for example, 2 standard deviations above the countryspecific mean. Note, however, that we are interested in large disasters where "large" is defined from a world wide perspective. While a given disaster might be large relative to the history of disasters within the country, it may be small in a more global context. Then, it is better to define a large disaster using the pooled world-wide mean. In this case, a disaster would be large when its magnitude exceeds 2 standard deviations above the world mean. ${ }^{12}$ In Figure 2 we present the distribution of disaster magnitudes.

Since the distribution is so skewed, the mean (plus one or two standard deviations) is a poor indicator of location, so we use a percentile-based definition of "large disaster". Thus, we consider the 99th, 90th and 75th percentiles of the world distribution of the number of people killed (as a share of population) as cutoff values that define a large disaster. The 99th cutoff

\footnotetext{
${ }^{12}$ In the analysis that follows, as it is standard in the literature, in order to eliminate potential outliers, we exclude data from countries with population levels below 1 million.
} 
Figure 2: Distribution of Disasters Magnitudes

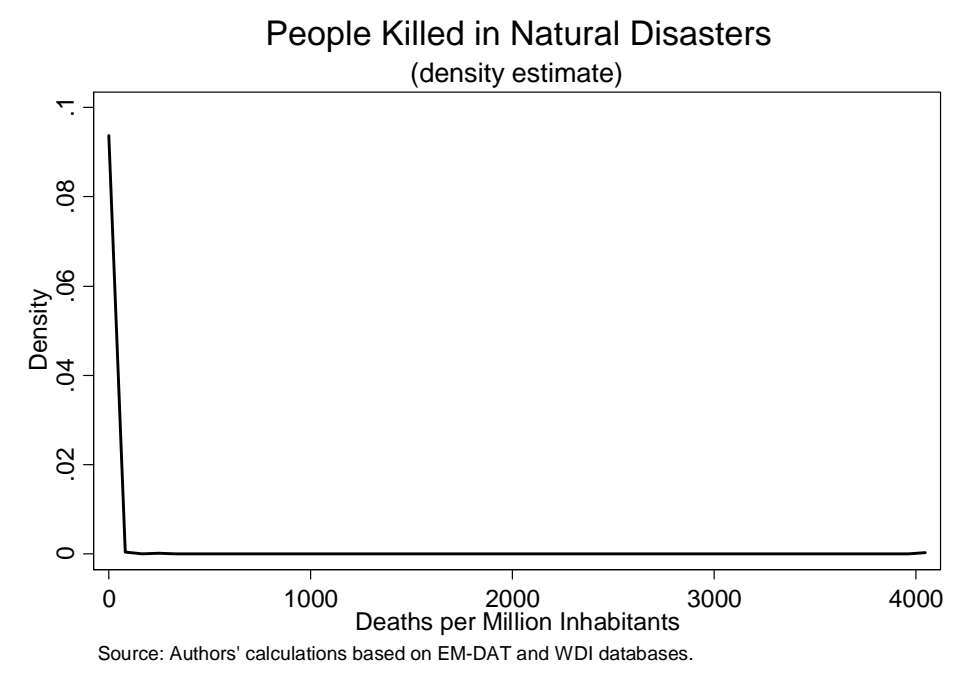

is equivalent to a natural disaster that kills more than 233 people per million inhabitants. The number is large, however many recent large events exceed this rate. For example, the 2004 Indian Ocean Tsunami killed 772 people per million inhabitants in Indonesia, and almost 2000 per million inhabitants in Sri Lanka. Moreover, by the latest accounts, the 2010 earthquake in Haiti killed over 20,000 people per million inhabitants (see Cavallo et al. (2010)). The 90th cutoff is equivalent to a natural disaster that kills approximately 17 people per million inhabitants. For example, this is within the estimated mortality range of the 2010 earthquake in Chile. Finally, the 75th cutoff corresponds to a natural disaster that would kill approximately 7 people per million inhabitants. This is approximately the mortality rate of Hurricane Katrina that struck the United States in 2005.

Moreover, the methodology we use requires that we can trace the evolution of the outcome variable for several years after the event. For that reason, we limit the sample to disasters that occur before the year 2000. Taking this into consideration, we end up with subsamples of 10 natural disasters that are large based on the 99th percentile, 164 natural disasters based on the 90th percentile, and 444 natural disasters based on the 75 th percentile cutoffs respectively.

However, we do not have full data on the GDP per capita predictors for all these events, and we were not able to construct valid counterfactuals for all the remaining natural disasters 
in our sample (i.e., there are natural disasters for which we could not match the pre-event GDP trajectory to that of a synthetic control group). ${ }^{13}$ Thus, the effective number of events in every subsample ends up being smaller. In particular, we end up with 4 events that are large based on the 99th percentile, 18 events based on the 90th percentile and 22 events based on the 75th percentile cutoffs respectively. See Table 4 in the Appendix for the list of events in each category. Finally, note that for some countries we have several "large disasters" over the sample period. In those cases we only use data before and after (up to the subsequent disaster) the first large disaster observed during the sample period. ${ }^{14}$

Obviously, the disaster magnitude as reported in the dataset is a combination of the physical intensity of the underlying event with the economic conditions of the affected countries. Nevertheless, in our view, that is the best estimate of the magitude of the shock to the economy, and hence the potential causing variable in our study.

Still, it is interesting to examine which of the magnitude variables correlates more with pure physical measures of disaster intensity such as Richter scale for earthquakes and wind speed for storms. Unfortunately the disaster intensity data is less readily available so we can perform the analysis only for a limited set of events. ${ }^{15}$ The following table shows the correlations between these physical measures of disasters and our damage measures for disaster magnitude.

\footnotetext{
${ }^{13}$ Identification relies heavily on matching the pre-treatment secular behavior of the outcome variable of interest. Thus, discarding from the analysis the unmatched events is similar to confining the analysis to the common support when using matching estimators.

${ }^{14}$ Then, when defining large disasters according to the different percentile cutoffs, what qualifies as a first disaster for a highest percentile cutoff does not necessarily coincide with what qualifies as first disaster for a lower percentile cutoff.

${ }^{15}$ Information taken from the database of the National Oceanic and Atmospheric Administration (NOAA). http://www.noaa.gov/.
} 
Table 3: Physical and Damage Measures of Disasters Magnitude Variables (Disaster level Data)

\begin{tabular}{|c|c|c|c|c|c|c|}
\hline \multirow[b]{2}{*}{ Richter scale (log) } & \multicolumn{2}{|c|}{$\begin{array}{l}\text { Damage over GDP } \\
\text { (log) }\end{array}$} & \multicolumn{2}{|c|}{$\begin{array}{l}\text { Killed over population } \\
\text { (log) }\end{array}$} & \multicolumn{2}{|c|}{$\begin{array}{c}\text { Affected over population } \\
\text { (log) }\end{array}$} \\
\hline & $\begin{array}{l}4.556^{\star \star \star} \\
{[1.166]}\end{array}$ & & $\begin{array}{l}7.951^{\star \star \star} \\
{[0.944]}\end{array}$ & & $\begin{array}{l}5.379^{\star \star \star} \\
{[0.832]}\end{array}$ & \\
\hline Wind Speed (log) & & $\begin{array}{l}2.464^{\star * *} \\
{[0.452]}\end{array}$ & & $\begin{array}{l}0.965^{\star \star \star} \\
{[0.241]}\end{array}$ & & $\begin{array}{l}1.771^{* * \star} \\
{[0.368]}\end{array}$ \\
\hline Land Area (log) & $\begin{array}{l}-1.030^{\star \star *} \\
{[0.105]}\end{array}$ & $\begin{array}{l}-0.393^{\star * *} \\
{[0.0862]}\end{array}$ & $\begin{array}{l}-0.955^{\star \star \star} \\
{[0.0764]}\end{array}$ & $\begin{array}{l}-0.521^{* * *} \\
{[0.0475]}\end{array}$ & $\begin{array}{l}-0.686^{\star \star *} \\
{[0.0795]}\end{array}$ & $\begin{array}{l}-0.196^{\star * *} \\
{[0.0532]}\end{array}$ \\
\hline Island state dummy & $\begin{array}{l}-2.387^{* * *} \\
{[0.530]}\end{array}$ & $\begin{array}{l}-0.347 \\
{[0.456]}\end{array}$ & $\begin{array}{l}-2.483^{\star * *} \\
{[0.473]}\end{array}$ & $\begin{array}{l}-0.239 \\
{[0.229]}\end{array}$ & $\begin{array}{l}-2.161^{* * *} \\
{[0.522]}\end{array}$ & $\begin{array}{l}1.634^{\star \star *} \\
{[0.343]}\end{array}$ \\
\hline Latitude (absolute value) & $\begin{array}{c}0.0143 \\
{[0.0115]}\end{array}$ & $\begin{array}{l}-0.0503^{\star * \star} \\
{[0.0143]}\end{array}$ & $\begin{array}{c}0.00523 \\
{[0.00840]}\end{array}$ & $\begin{array}{l}-0.0590^{* * *} \\
{[0.00728]}\end{array}$ & $\begin{array}{c}0.00797 \\
{[0.00815]}\end{array}$ & $\begin{array}{l}-0.115^{\star \star *} \\
{[0.0167]}\end{array}$ \\
\hline Constant & $\begin{array}{c}2.324 \\
{[2.425]}\end{array}$ & $\begin{array}{l}-8.839^{* * *} \\
{[2.765]}\end{array}$ & $\begin{array}{c}-2.664 \\
{[1.941]}\end{array}$ & $\begin{array}{l}2.675^{\star \star} \\
{[1.311]}\end{array}$ & $\begin{array}{l}3.783^{* *} \\
{[1.677]}\end{array}$ & $\begin{array}{c}1.824 \\
{[1.975]}\end{array}$ \\
\hline r2 & 0.320 & 0.333 & 0.320 & 0.504 & 0.164 & 0.395 \\
\hline $\mathrm{N}$ & 232 & 255 & 428 & 375 & 594 & 384 \\
\hline
\end{tabular}

Population killed by the disaster correlates better with the exogenous measures in the sense of having a higher goodness of fit for both measures. Moreover, whether a person was killed is a more precisely defined event than say, whether a person was affected by the disaster. Also, number of people killed is more comparable across countries than value-based measures. We will then use number of people killed as our disaster magnitude variable when selecting a pool of large disasters.

\section{Results}

In this section we present our estimates of the average causal impact of large disasters on real GDP per capita for countries that experienced such large disasters between 1970 and 2000 and that have the available data required for a comparative case study. Recall that for those countries that experienced several large disasters only the first is used, and their post disaster data is only used up to the year preceding the 2nd large disaster.

\subsection{Overall Effects}

Like in the program evaluation literature, our estimator does not disentangle between direct and indirect causal effects of the natural disasters on the outcome of interest. It just estimates 
the overall average causal effect. Though this is always an important distinction, in our case, however, it is not clear-cut how to draw the line between those effects. Indeed, it might well be argued that all of the total effect of natural disasters on economic growth is indirect. With this caveat in mind we now present our estimates of the overall average causal effects of natural disasters on economic growth.

Figures 3, 5 and 7 present the average causal impact of a large disaster on real GDP per capita for the three different definitions of "large disaster" adopted: P99, P90 and P75. $\mathrm{P}^{\prime \prime} X^{\prime \prime}$ for $X=75,90$, and 99 denotes the group of countries exposed to disasters in which the magnitude of the disaster was above the $X^{\text {th }}$ percentile in the world distribution of disaster damages.

Figure 3: Large Disasters = above 99 Percentile

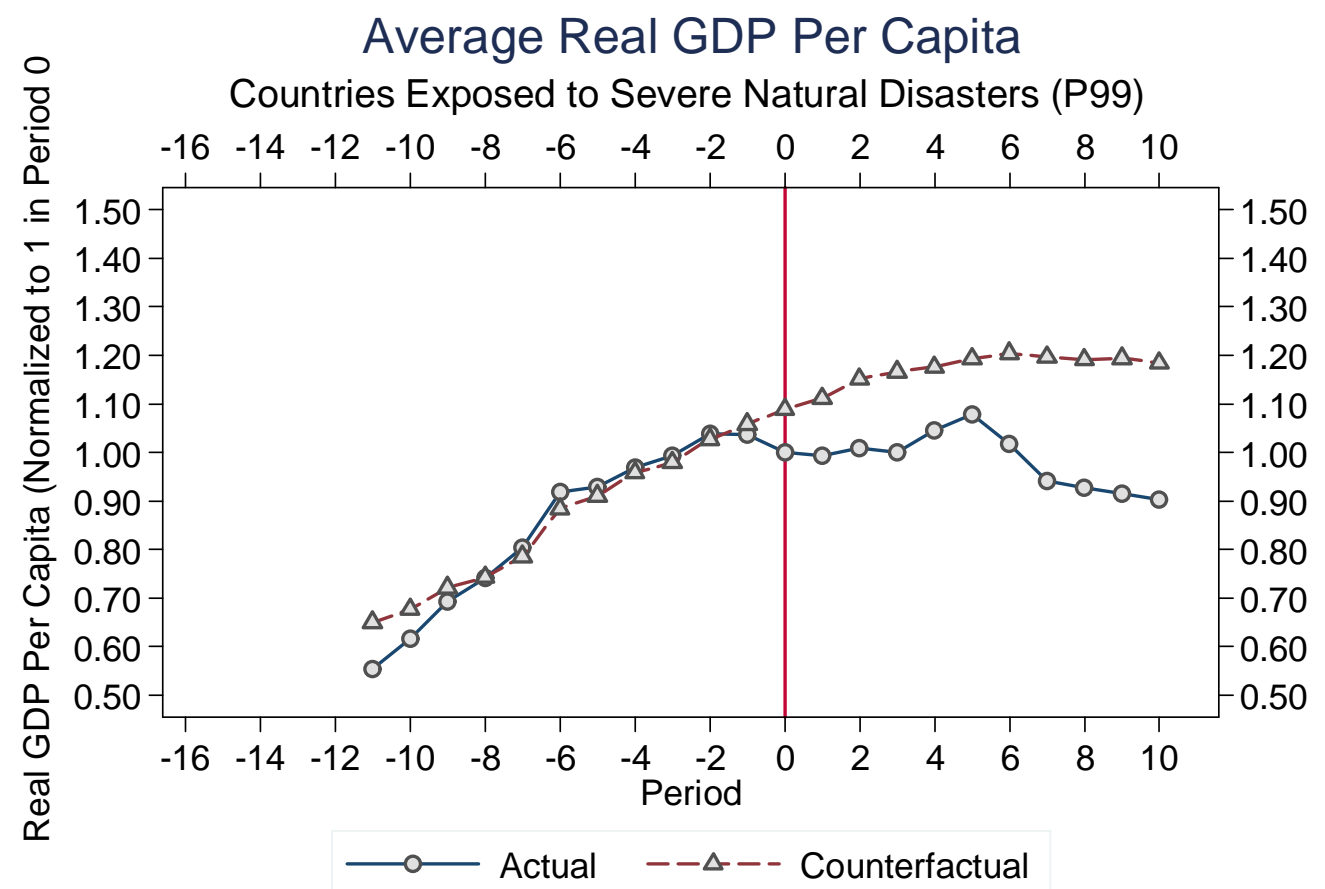

Note: Average taken across large disaster countries without missing data

As can be seen, large disasters seem to have a lasting impact on GDP per capita when we define a large disaster to be one above the 99th percentile of the magnitude distribution. The effects are sizable. For example, ten years after the disaster, the GDP per capita of the affected countries is (on average) $10 \%$ lower that it was at the time of the disaster 
whereas it would be about $18 \%$ higher in the counterfactual scenario in which the disaster did not occur. Moreover, note that by extrapolating the pre-disaster trend into post-disaster years to construct the counterfactual, we would be over-estimating the effect of the disaster. In Figure 4 we present exact inference for the results in the P99 group. When computing placebo averages, we refine our inference approach and include only the averages computed with placebos for which we obtained as good a pre-treatment fit as the country that they serve as donors for. Thus, this evidence suggest that a natural disaster would cause, on average, a statistically significant decline in GDP per capita in all the 10 years in its aftermath. The probability of observing such declines by pure chace is close to zero in every period.

Figure 4: Adjusted Significance Levels for P99

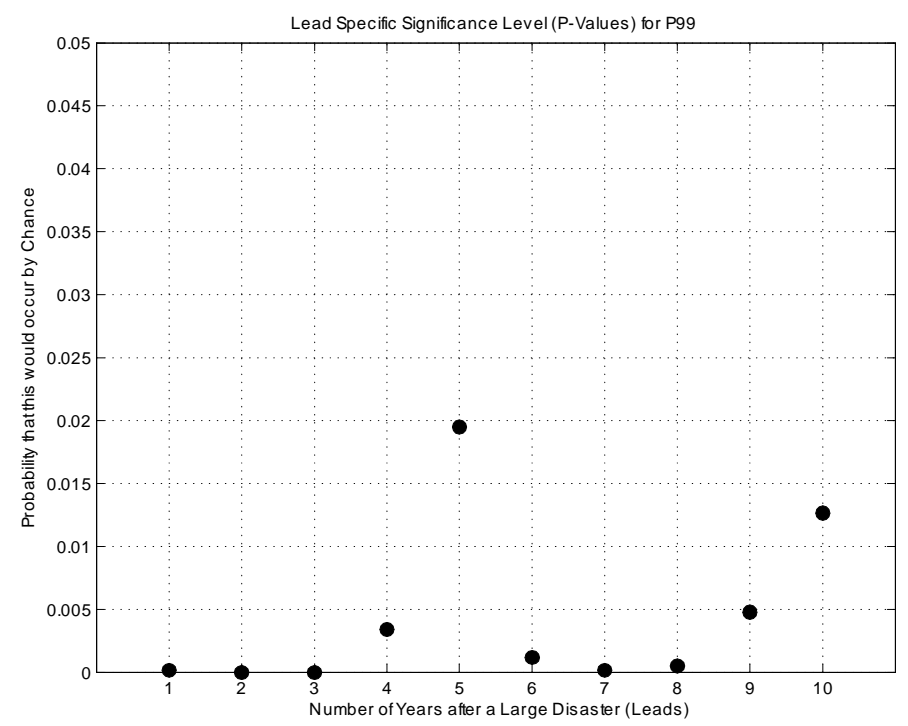

In Figure 5, where we define a large disaster using the 90th percentile, we do not find any effect of disasters on output. Actual and counterfactual GDP per capita follow each other closely, not only before but also after the occurrence of the disaster. Whatever slight difference we find between them, it is not statistically significant at conventional levels (See Figure 6).

Again, considering our most lenient definition of large disaster using the 75th percentile (P75) in Figure 7, we do not find any effect of disasters on output. As can be seen in 
Figure 5: Large Disasters = above 90 Percentile

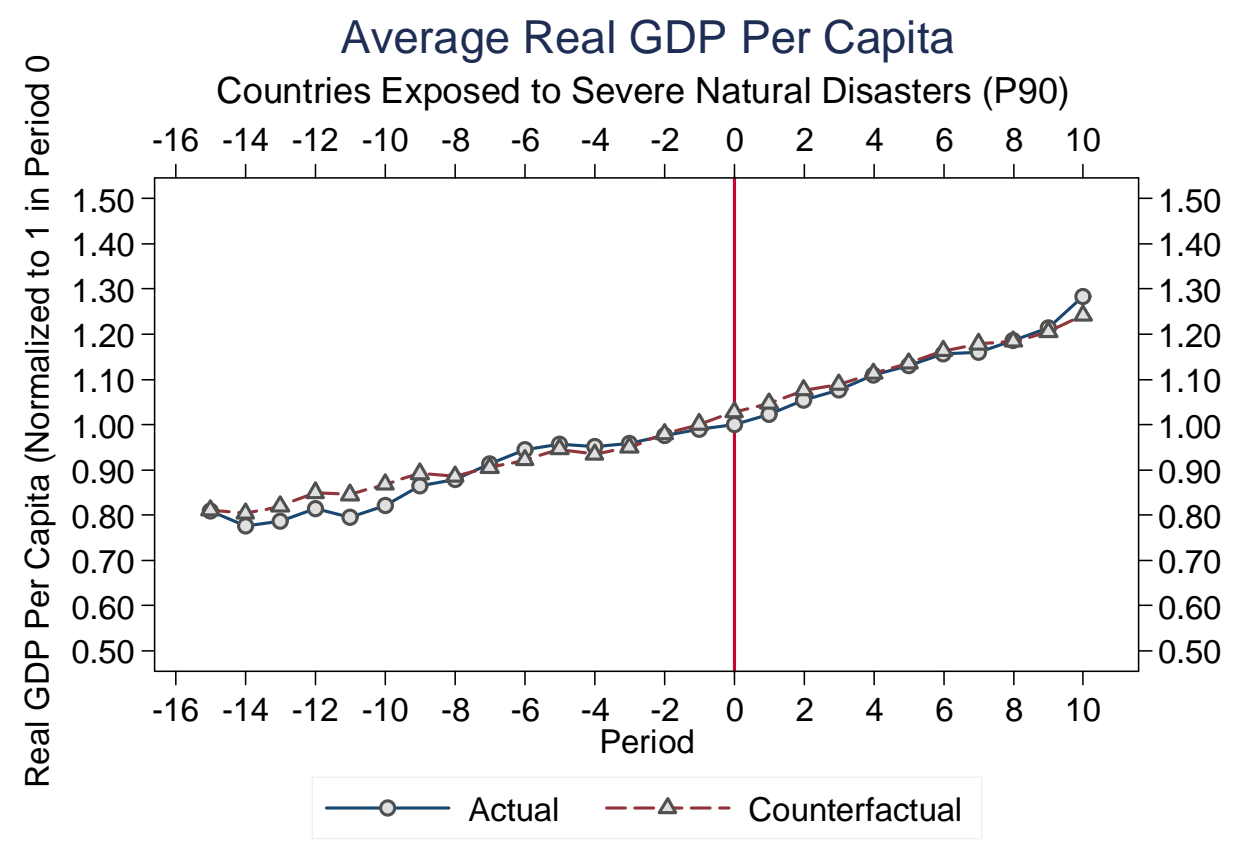

Note: Average taken across large disaster countries without missing data

Figure 6: Adjusted Significance Levels for P90

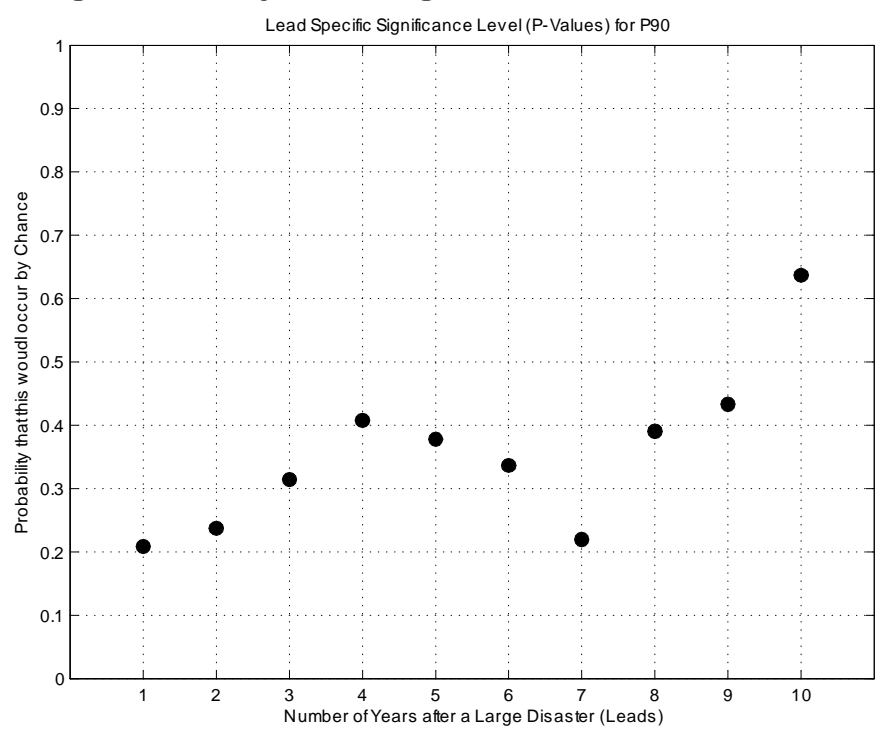


Figure 7: Large Disasters = above 75 Percentile

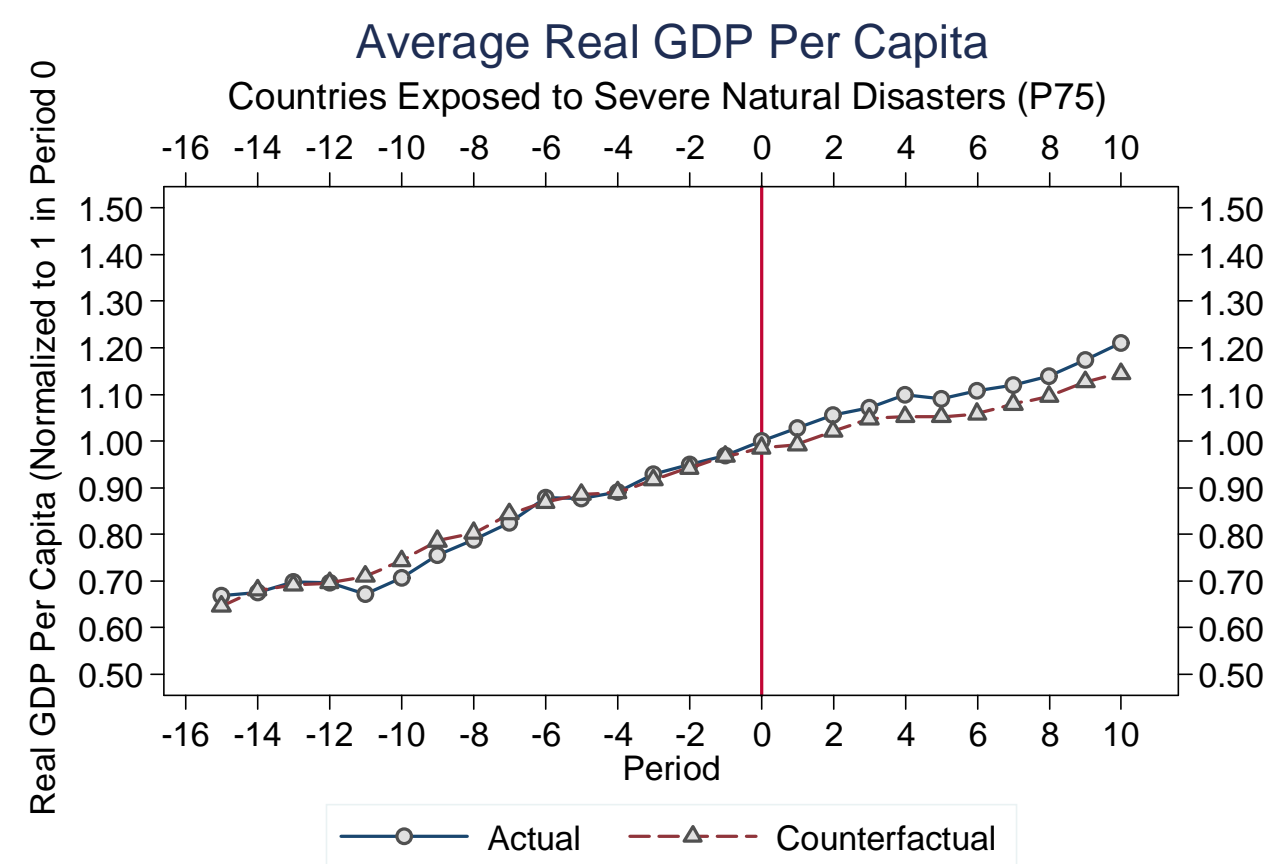

Note: Average taken across large disaster countries without missing data

Figure 8, none of the differences between the actual and counterfactual GDP per capita are statistically significant.

Taken at face value, these results suggest that only large natural disasters affect, on average, the subsequent performance of the economy. For example, one can use our results to estimate the likely long-term impact of the catastrophic earthquake that struck Haiti on January 12, 2010. By the metric of the number of fatalities as a share of population, the Haiti earthquake is the most catastrophic one in the modern era, killing as many as five times more people per million inhabitants than the worst event in our comprehensive sample (i.e., the 1972 earthquake in Nicaragua). If Haiti were to experience the average long-term impact of a P99 disaster we estimate, by 2020 it would have an income per capita of $\$ 1060$ while it could have had a per capita income of about $\$ 1410$ had the earthquake not occurred (all figures in PPP 2008 international dollars). Instead, the devastating earthquake that struck Chile on February 27th 2010, one of the strongest earthquakes ever recorded, is also an informative case to consider. According to recent information from the Chilean government 
Figure 8: Adjusted Significance Levels for P75

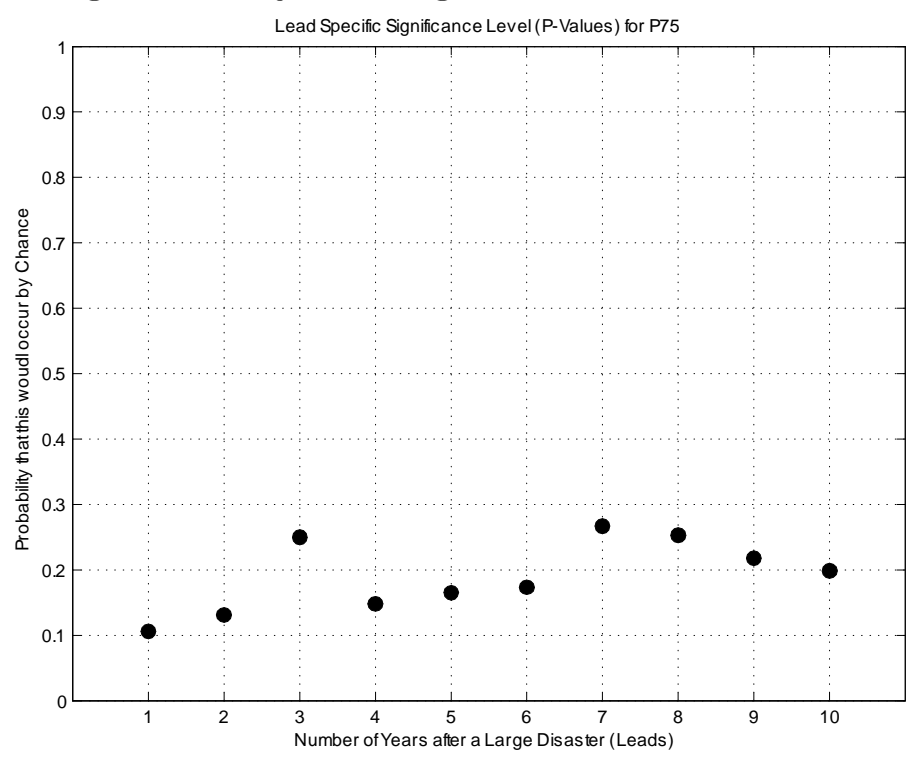

(as of $3 / 20 / 2010$ ), the earthquake killed 342 people out of a population of approximately 17 million (this is within the mortality range of our P90 subsample). By our estimates, such an event is not likely to generate long-term adverse impact on per capita GDP.

\subsection{Effects Controlling for Radical Political Revolutions}

Two of the four disasters in the 'treated' group of very large disasters (i.e., those defined by the 99th cutoff) were followed by political revolutions. These were the cases of 1979 Islamic Iranian Revolution, which occurred right after the 1978 earthquake and the Sandinista revolution in Nicaragua that deposed the Somoza Dynasty also in 1979, a few years after the earthquake that devastated Managua. Though it is possibly that these natural disasters somehow affected the likelihood of those radical political revolutions, we cannot substantiate such a causal claim. ${ }^{16}$ Irrespective of that, in the structural spirit of analyzing the effect of the natural disasters on economic growth controlling for the effect of these political revolu-

\footnotetext{
${ }^{16}$ Nevertheless, in the case of Nicaragua, it has been argued that the 1972 earthquake that devastated Managua played a role in the fall of Somoza. Instead of helping to rebuild Managua, Somoza siphoned off relief money to help pay for National Guard luxury homes, while the homeless poor had to make do with hastily constructed wooden shacks. This greatly contributed to erode the remaining support of Somoza's regime among many businessmen and the middle class (see, among others, Merrill 1993). In the case of Iran, the earthquake served the organization of the revolution, in particular, by having coordinated the organization of Khomeini's Revolutionary Guard that latter played a key role in advancing the revolution activities (see Keddie, 2006).
} 
Figure 9: Large Disasters Not Followed by Political Revolutions

Average Real GDP Per Capita w/o Revolutions
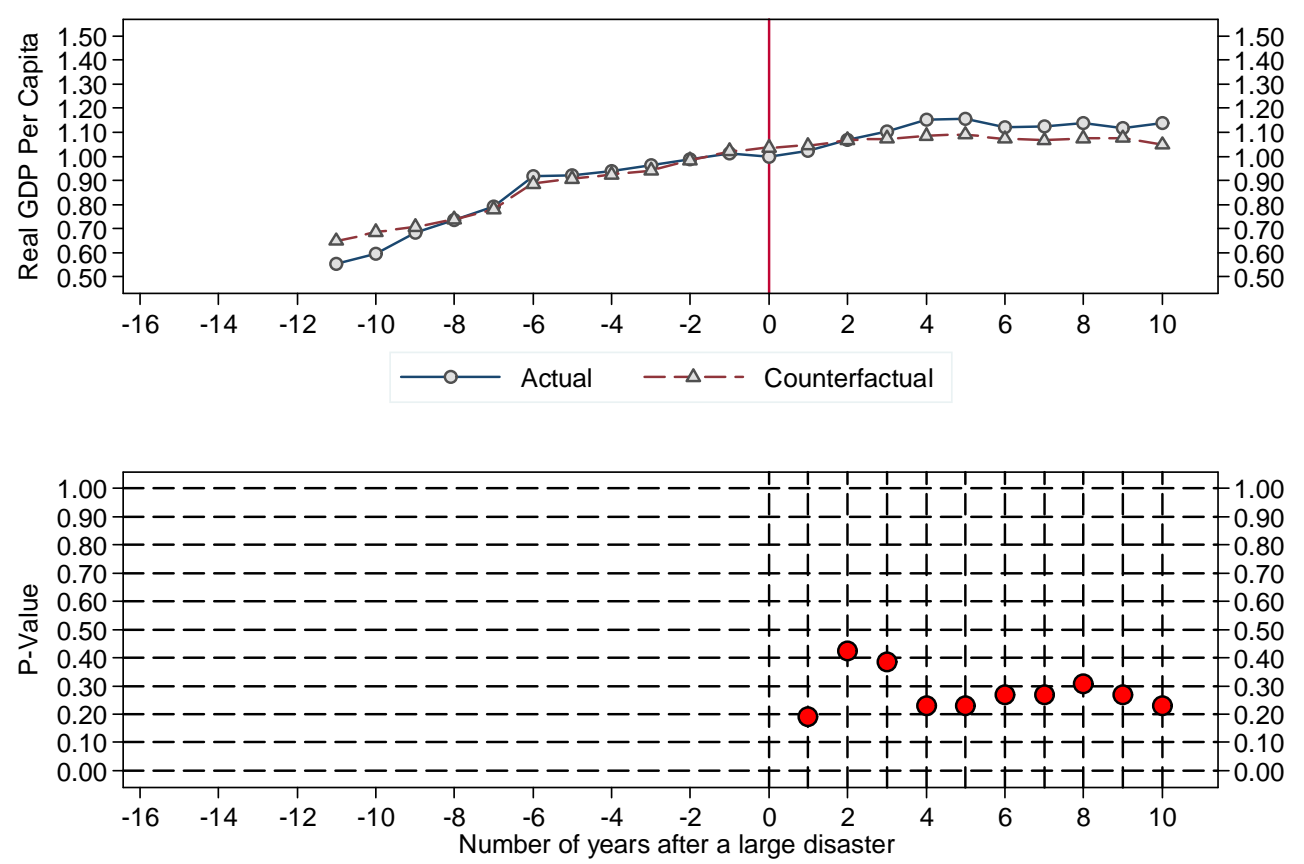

tions, it is of interest to separate the analysis between the cases where the natural disaster was followed by radical political revolution, as it was the case of Iran and Nicaragua, which certainly affected the working of the economy, and those that were not followed by political revolution, such as the cases of Honduras (1974) and Dominican Republic (1979) (see Table 4). ${ }^{17}$

Figures 9 and 10 present this analysis. In Figure 9 we observe that when we restrict the analysis to the subset of large disasters (in the 99th percentile) that were not followed by radical political revolutions, we find no effects of the disaster on GDP per capita. Neither in the short nor in the long run.

In Figure 10 we observe large long lasting effects of a catastrophic disaster when followed by radical political revolutions. As can be seen in the figure, the earthquakes in Nicaragua

\footnotetext{
${ }^{17}$ Of course, if the disasters did not caused the political change, the overal average effect previously estimated would be biased upward (in absolute value) due to these subsequent negative shocks correlated with the treatment indicator used in the analysis.
} 
Figure 10: Large Disasters Followed by Political Revolutions
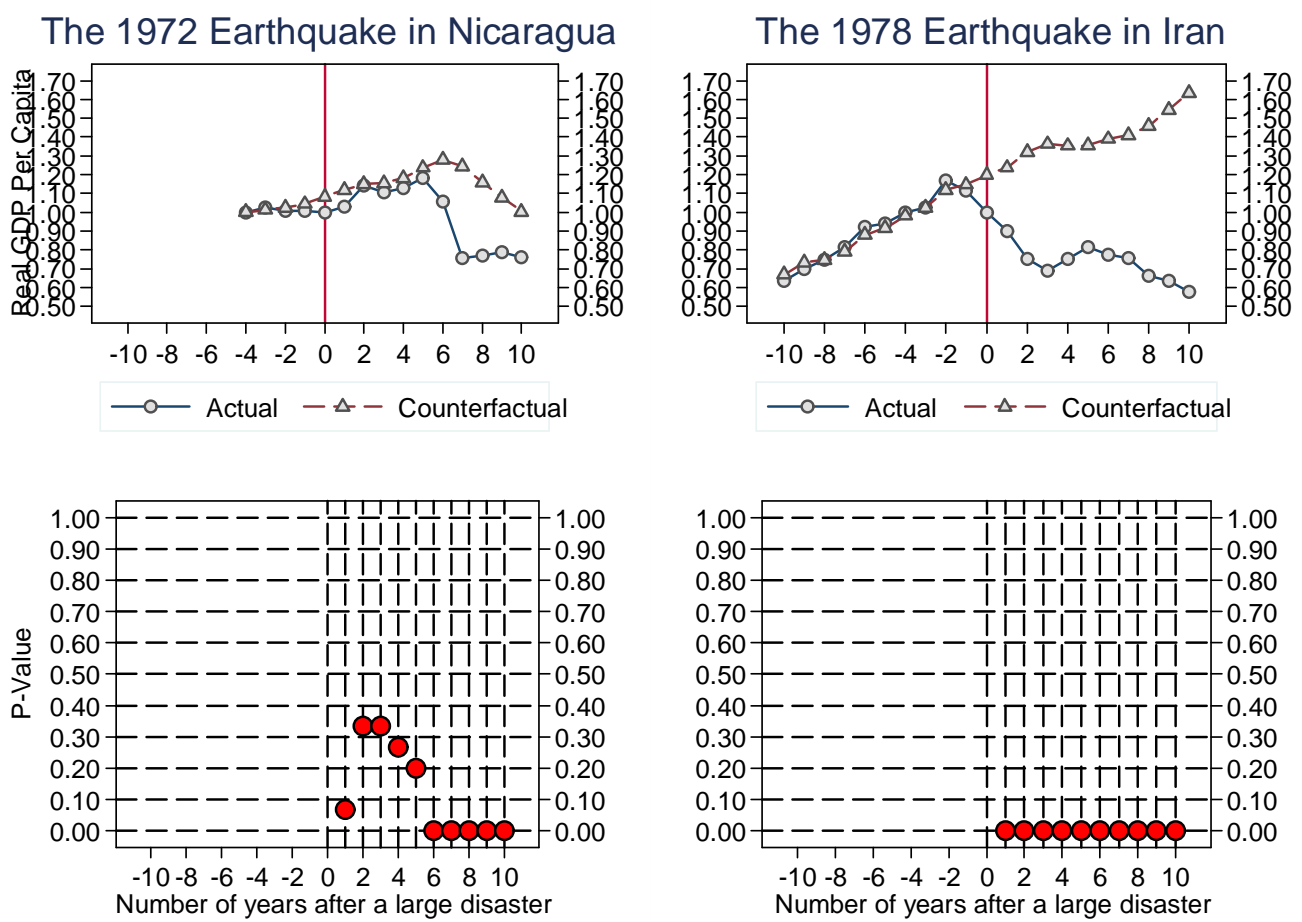

and Iran produced large and statistically significant effects on output per capita. Note, however, that Nicaragua, after a short-lived (1-year) small but statistically significant decline, was fully recovering from the disaster (in terms of GDP per capita). However, it dropped again, in a much more pronounced way, with the revolution, six to seven years after the disaster. This result confirms, once again, the salient importance of the political organization of societies in determining their economic performance (see, among others, Acemoglu et al., 2005).

Thus, we find that only very large natural disasters followed by radical political revolution show long-lasting negative economic effects on economic growth. Even very large natural disasters, when not followed by disruptive political reforms that alter the economic system, including the system or property rights, do not display significant effects on economic growth. $^{18}$

\footnotetext{
${ }^{18}$ Excluding Iran and Nicaragua from the analysis for the 90th and 75 th cutoff points does not change the analysis significantly.
} 


\section{Conclusions}

We examined the impact of natural disasters on GDP per capita by combining information from comparative case studies obtained with a synthetic control methodology recently expounded in Abadie et al. (2010). The procedure involves identifying the causal effects by comparing the actual evolution of post-disaster per capita incomes with a counter-factual series constructed by using synthetic controls.

Our estimates provide new evidence on the short- and long-run per capita income effects of large natural disasters. Contrary to previous work, we find that natural disasters, even when we focus only on the effects of the largest natural disasters, do not have any significant effect on subsequent economic growth. Indeed, the only two cases where we found that truly large natural disasters were followed by an important decline in GDP per capita were cases where the natural disaster was followed, though in one case not immediately, by radical political revolution, which severely affected the institutional organization of society. Thus, we conclude that unless a natural disaster triggers a radical political revolution; it is unlikely to affect economic growth. Of course, this conclusion does not neglect the direct cost of natural disasters such as the lives lost and the costs of reconstruction that often are quite large.

Finally, our results are informative about the average long-term costs of natural disasters; and can also be useful to other literatures such as those attempting to quantify the likely costs of any future climate change and evaluating various climate-change mitigation policies. 


\section{References}

[1] Albala-Bertrand J M. (1993), Political economy of large natural disasters, Oxford: Clarendon Press.

[2] Abadie and Gardeazabal (2003), The Economic Costs of Conflict:A Case Study of the Basque Country, American Economic Review.

[3] Abadie, Diamond and Hainmueller (2010), Synthetic Control Methods for Comparative Case Studies: Estimating the Effects of California's Tobacco Control Program, Journal of the American Statistical Association.

[4] Acemoglu, D., S. Johnson and J. Robinson (2005), Institutions as a Fundamental Cause of Long-Run Growth, in P. Aghion and S. Durlauf (eds.), Handbook of Economic Growth, North-Holland.

[5] Barro, R. and X. Sala-i-Martin (2003), Economic Growth, MIT Press.

[6] Barro, R. (2006), Rare Disasters and Asset Markets in the Twentieth Century. Quarterly Journal of Economics 121: 823-866.

[7] Barro, R. (2009), Rare Disasters, Asset Prices, and Welfare Costs. American Economic Review 99(1): 243264.

[8] Caballero and Hammour (1994), The Cleansing Effect of Recessions, American Economic Review, Volume 84, No. 5, (December 1994), pp. 1350-1368

[9] Cavallo, E. and Noy, I. (2009), The Economics of Natural Disasters: A Survey, IDB Working Paper 124. Washington DC, united States: Inter-American Development Bank.

[10] Cavallo, E., A. Powell and O. Becerra (2010), Estimating the Direct Economic Damage of the Earthquake in Haiti. Forthcoming: Economic Journal

[11] Easterly, Willliam, and Levine, Ross (2001), "It's Not Factor Accumulation: Stylized Facts and Growth Models" World Bank Economic Review, Volume 15, Number 2 
[12] Kahn M E. (2004), The death toll from natural disasters: The role of income, geography, and institutions. Review of Economics and Statistics, 87(2); 271-284.

[13] Keddie, N. (2006). Modern Iran: Roots and Results of Revolution, Yale University Press.

[14] Kellenberg, Derek K., and Ahmed Mushfiq Mobarak (2008), Does rising income increase or decrease damage risk from natural disasters? Journal of Urban Economics 63, 788802.

[15] Lutz W, A Goujon, S K.C., W Sanderson (2007), Reconstruction of population by age, sex and level of educational attainment of 120 countries for 1970-2000. Vienna Yearbook of Population Research, vol. 2007, pp 193-235.

[16] Mankiw, N. Gregory, David Romer, and David Weil (1992), "A Contribution to the Empirics of Economic Growth," Quarterly Journal of Economics, CVII, 407-437.

[17] Marshall, M., and K. Jaggers (2002), "Polity IV Project: Political Regime Characteristics and Transitions, 1800-2002: Dataset Users' Manual." College Park, Maryland, United States: University of Maryland. www.cidcm.umd.edu/inscr/polity.

[18] Merril, Tim (1993), Nicaragua: A Country Study. Washington: GPO for the Library of Congress.

[19] Noy, Ilan (2009), The Macroeconomic Consequences of Disasters. Journal of Development Economics, 88(2), 221-231.

[20] Raddatz Claudio (2007), Are external shocks responsible for the instability of output in low-income countries? Journal of Development Economics 84; 155-187.

[21] Yang, D. (2008), Coping with Disaster: The Impact of Hurricanes on International Financial Flows, 1970-2002, B. E. Journal of Economic Analysis \& Policy: Vol. 8, No. 1 (Advances), Article 13. 


\section{Appendix}

Table 4: Events Included in Each Percentile-Based Defintion of Large Event

\begin{tabular}{|c|c|c|c|c|c|}
\hline Country & Yoar & Decoription ${ }^{14}$ & Nollod & $\begin{array}{l}\text { Population } \\
\text { (thoucanda) }\end{array}$ & $\begin{array}{c}\text { Destinc per million } \\
\text { Inhabitants }\end{array}$ \\
\hline \multicolumn{6}{|c|}{ Pes } \\
\hline Nicaragua & 1972 & Earthquake (1) & 10,000 & 2,551 & $4,046.0$ \\
\hline Honduras & 1974 & Stom (1) & 8,000 & 3,014 & $2,733.2$ \\
\hline Iran talam Rep & 1978 & Earthquake (2) & 25,045 & 36,554 & 7076 \\
\hline Dominican Rep & 1979 & Stom (1) and food (1) & 1,432 & 5,800 & 2528 \\
\hline \multicolumn{6}{|c|}{ Peo } \\
\hline Ncarogua & 1972 & Earthquake (1) & 10,000 & 2,551 & $4,046.0$ \\
\hline Hondurss & 1974 & Storm (1) & 8,000 & 3,014 & $2,733,2$ \\
\hline Dominican Rep & 1979 & Starm (1) and flood (1) & 1,432 & 5,800 & 252.8 \\
\hline Iran lelam Rep & 1972 & Earthquake (1) and storm (1) & 5,117 & 30,269 & 174.3 \\
\hline Meroco & 1985 & Earthquake (1) & 9,500 & 75,465 & 128.5 \\
\hline Paklatan & 1974 & Earthquake (1) & 4,700 & 68,813 & 70.5 \\
\hline Bollva & 1983 & Flood (1) & 250 & 5,714 & 44.7 \\
\hline Ecuador & 1982 & Food (1) & 307 & 8,409 & 37.5 \\
\hline Colombla & 1999 & Earthquake (1), stom (1) and food I & 1,229 & 41,004 & 30.5 \\
\hline Hong Kong (China) & 1971 & stom (1) & 115 & 4,045 & 29.0 \\
\hline Phillppines & 1972 & Starm (3) and flood (1) & 1,088 & 38,670 & 28.9 \\
\hline Turkey & 1971 & Earthquake (2) & 935 & 36,238 & 26.5 \\
\hline Indla & 1977 & Stam (2) and flood (2) & 14,766 & 642,100 & 23.5 \\
\hline Korea Rep & 1972 & Flood (2) & 747 & 33,266 & 22.9 \\
\hline Sn Lanka & 1989 & Food (1) & 325 & 16,825 & 19.6 \\
\hline Peru & 1971 & Flood (1) & 250 & 13,567 & 18.9 \\
\hline Costa Rica & 1996 & Stbrm (2) and flood (1) & 60 & 3,563 & 17.3 \\
\hline taly & 1976 & Earthquake (2) & 934 & 55,718 & 16.8 \\
\hline \multicolumn{6}{|c|}{ P76 } \\
\hline Honduras & 1974 & storm (1) & 8,000 & 3,014 & $2,733.2$ \\
\hline Dominican Rep & 1979 & Stom (1) and flood (1) & 1,432 & 5,800 & 2528 \\
\hline Iran lalam Rep & 1972 & Earthquake (1) and storm (1) & 5,117 & 30,269 & 174.3 \\
\hline Ecusdor & 1982 & Flood (1) & 307 & 8,409 & 37.5 \\
\hline Hong Kong (China) & 1971 & Storm (1) & 115 & 4,045 & 29.0 \\
\hline Turtey & 1971 & Earthquake (2) & 935 & 36,238 & 26.5 \\
\hline Indla & 1977 & Starm (2) and flood (2) & 14,766 & 642,100 & 23.5 \\
\hline Paraguay & 1983 & Food (1) & 76 & 3,400 & 23.0 \\
\hline Korea Rep & 1972 & Food (2) & 747 & 33,266 & 22.9 \\
\hline Snt Lanka & 1989 & Food (1) & 325 & 16,825 & 19.6 \\
\hline Peru & 1971 & Food (1) & 250 & 13,567 & 18.9 \\
\hline bly & 1976 & Earthquake (2) & 934 & 55,718 & 16.8 \\
\hline Colombla & 1979 & Earthquake (2) and flood (1) & 422 & 27,729 & 15.6 \\
\hline Spain & 1973 & Stom (1) and flood (1) & 519 & 34,810 & 15.1 \\
\hline Nicarsoua & 1971 & Storm (1) & 35 & 2,472 & 14.6 \\
\hline Indonesla & 1973 & stom (1) & 1,650 & 126,400 & 13.4 \\
\hline Thaland & 1988 & Flood (1) & 664 & 52,948 & 12.7 \\
\hline Mexico & 1973 & Earthquake (2) and flood (2) & 647 & 55,641 & 12.0 \\
\hline Costa Rica & 1973 & Earthquake (1) & 21 & 1,955 & 11.0 \\
\hline Chle & 1984 & stom (2) & 127 & 11,903 & 10.8 \\
\hline Pakiatan & 1973 & Flood (1) & 474 & 66,652 & 73 \\
\hline Portugal & 1980 & Earthquake (1) & 69 & 9,766 & 7.1 \\
\hline Kenya & 1977 & Food (1) & 100 & 14,549 & 7.1 \\
\hline Bollva & 1974 & Flood (1) & 31 & 4,644 & 6.8 \\
\hline Phillppines & 1971 & Starm (4) & 246 & 37,602 & 6.7 \\
\hline Nustralla & 1974 & storm (2) and flood (1) & 90 & 13,723 & 6.7 \\
\hline Greece & 1979 & Earthquake (1) and food (1) & 63 & 9,548 & 6.7 \\
\hline
\end{tabular}

Notes: (a) The number in parenthes ls refer to the number of events occurred in this year. For example, stoms (4) implies that four stoms occurred in a country in a given year.

Source: Authors' calculation based on EMFDAT and WOI databases. 